\title{
Breast Cancer Statistics in the European Union: Incidence and Survival across European Countries
}

\author{
Urania Dafni ${ }^{a}$ b Zoi Tsourti ${ }^{b}$ Ioannis Alatsathianos ${ }^{b}$ \\ a Laboratory of Biostatistics, Faculty of Nursing, National and Kapodistrian University of Athens, Athens, Greece; \\ ${ }^{b}$ Frontier Science Foundation Hellas, Athens, Greece
}

\section{Keywords}

Breast cancer · Epidemiology · Incidence · Survival rate . European Union

\section{Abstract}

The current status and time trends in breast cancer incidence and survival in the 28 European Union countries (EU-28) is presented here. Rates reported are age adjusted and standardized (ASR). A high incidence and high survival rates were observed in the Northern and Western European countries, with the exception of the Baltic countries. The higher incidence is partly attributed to the higher prevalence of lifestyle risk factors, while the higher survival is attributed to better access to beneficial treatments and general health care. Most of the countries in Southern Europe or the former Eastern Bloc have not yet reached the high GDP per capita status (2017 purchasing power parity; PPP) of the earlier established Western democracies. The breast cancer incidence and survival are associated with the PPP level (both higher for the higher PPP category; 2017 PPP above USD 40,000). Overall, a trend toward higher survival rates was observed throughout this first period of the 21st century, with the incidence for most countries either stabilizing at the 2010 levels or decreasing further.

๑) 2019 S. Karger AG, Base
\end{abstract}

\section{Introduction}

\section{Breast Cancer in the European Union}

In 2018, according to the prediction of the European Cancer Information System (ECIS), breast cancer continues to be the most common female cancer, with the incidence in the European Union (EU-28) accounting for $29.2 \%$ of all cancers in women [1]. In the EU-28 countries, a total of 404,920 new female breast cancer cases was estimated to occur in 2018, corresponding to an age-adjusted standardized rate (ASR) of 144.9/100,000 [1, 2]. Breast cancer represents a major Public Health concern due to its high morbidity and mortality rates [3], with EUROSTAT reporting that it accounted for $1.8 \%$ of all deaths in the EU-28 in 2015 and 3.6\% (i.e., double) of deaths in women $[4,5]$.

Breast cancer was the leading cause of death from cancer in women $(138,000 ; 16.2 \%$ of 850,000 cancer deaths) [6] among 40 European countries in 2018, but it was reported as the second cause after lung cancer in the EU-28, with EU breast cancer mortality rates declining from 17.9/100,000 in 2002 to 15.2 in 2012; (rates predicted for 2020 to further decline to 13.4) $[6,7]$.

A high incidence of breast cancer is seen in developed countries. All EU-28 countries are currently classified by the United Nation (UN) as developed economies, with the majority being high-income (more recently Latvia and Hungary) and only 2, i.e., Bulgaria and Romania, both from the former Eastern European Bloc, categorized as upper-middle-income countries [8]. Nevertheless,

\section{KARGER}

(C) 2019 S. Karger AG, Basel 
some of important risk factors, such as a Western lifestyle pattern, including an unhealthy diet, obesity, and consumption of alcohol [2], urbanization and sedentary behavior [9] and parity, age at first pregnancy, breastfeeding practice and exposure to exogenous hormones including long-term hormone replacement therapy [2], could still diverge among European countries.

Other important risk factors that might differ between country populations include possibly differences in genetic predisposition, age distribution, and actual availability and access to treatment.

Regarding genetic predisposition, national guidelines differ on access to genetic counselling and testing, making it difficult to compare incidences of the relevant mutations across countries. For example, in France and Germany referral is not obligatory, although it is common, while in The Netherlands and the UK for referral from primary or secondary care a general practitioner or a specialist is required, respectively [10]. Population-based studies have reported a prevalence of mutations (BRAC1 and BRAC2) of around $0.2 \%$ in the general population, $1.6 \%$ in Inuits, $0.4 \%$ in Icelanders, and up to $2.5 \%$ in the Ashkenazi Jewish population [11]. With the advent of sequencing technology, more data is expected to accumulate [12] that will describe rigorously the possible impact of genetic predisposition on country-wide incidence and mortality rates.

Three quarters of breast cancer cases occur in individuals aged over 50 years, with an incidence of less than $5 \%$ in people aged up to 35 years. European demographic trends show an ageing population, with a median age of 41.9 years compared to the world median age of 29.2 years $[13,14]$. The ageing population in the EU will result in a further increase in the burden of breast cancer and its impact on public health.

The incidence and mortality of breast cancer in $\mathrm{Eu}-$ rope and the EU-28 have been reported extensively in the literature as a part of general cancer incidence publications or geographical region-specific data for different time periods.

In this paper, for the purpose of describing the current state of breast cancer incidence, mortality, and survival in the EU-28, historical or estimated data as presented in relevant databases are used along with available information in the literature. The databases included are available from the ECIS [1], the Institute for Health Metrics and Evaluation (IHME) [15], and the CONCORD-3 program [16]. The focus here is on female breast cancer, taking into account that in males breast cancer is rare, contributing only to approximately $1 \%$ of cases. The country-specific age distribution is taken into account by presenting ageadjusted incidence and mortality and net survival rates. Differing treatment access by country is also explored, emphasizing that in most Western countries the mortal- ity rate has decreased in recent years as a result of improvement in the outcomes of new treatments and earlier detection $[2,17]$.

\section{Methods}

Three major databases constitute the data sources for the incidence, mortality, and survival in Europe presented here. The first, i.e., the ECIS, is supported by the European Commission's Joint Research Centre and the Directorate General for Health and Food Safety (DG SANTE) and cooperates with cancer registries associated with the European Network of Cancer Registries [1]. The second, i.e., the Global Burden of Disease Database (GBD), is available at the IHME, an independent global health research center at the University of Washington [15]. The third is based on the CONCORD-3 program, which is a global program on cancer survival supported by 40 national and international organizations such as the WHO EURO, the Organization for Economic Cooperation and Development, and the World Bank [16].

For 2018 in the EU-28 countries, estimates of age-adjusted female breast cancer incidence and mortality rates standardized using the new European standard population (ASR -European new) were extracted from the ECIS database and presented by European region and overall. The ECIS includes historical incidence data for some countries (i.e., those where either national or regional registries exist) [1]. Thus, historical data on breast cancer incidence rates adjusted by age and sex from 1990 to 2017 were extracted from the GBD database of the IHME for all EU-28 countries. The updated GBD world population standard was used for age-standardized rate calculation. This updated standard uses the original WHO 2001 standard adjusted by the $2010-2035$ population estimates [15]. Of note, 2018 incidence estimates (from the ECIS) are not directly comparable to IHME historical data due to different approaches in standardization.

For data on survival, the primary source of information are the CONCORD-3 program studies [16]. Data is provided for all adults and not separately by sex. Nevertheless, it is used here as a good surrogate for female breast cancer survival, recognizing the rarity of breast cancer incidence in men. The 5-year net survival in CONCORD-3 was age standardized with the International Cancer Survival Standard weights [16]. Net 5-year survival rates for all adults (15-99 years old) diagnosed with breast cancer in EU countries except for Greece, Hungary, and Luxembourg for 2000-2004, 2005-2009, and 2010-2014 are available.

For 2018, breast cancer incidence (ASR) and 5-year survival rates (most recently reported in 2014) are presented in a geographic regional map (Fig. 1a, b), and both incidence and mortality are shown in a pyramid plot (Fig. 2), while line plots by year are presented for historical incidence and survival rates (Fig. 3a, b).

In addition, 1- and 5-year relative breast cancer survival data rates by age group are presented in line plots (Fig. 4). They were extracted from the ECIS for all EU-28 countries with available data (not available: Greece, Cyprus, UK, Hungary, Luxembourg, and Romania). These survival data were conveyed from countries and registries for survival analysis for the period of 2000-2007 to the Eurocare-5 database using a slightly different geographic characterization. The difference in categorization of regions amounts to Northern Europe including all countries as before except for the Baltic countries, which are now included in Eastern Europe; the Central European region now includes the countries previously included in the Western European region, while Southern Europe remains the same. 


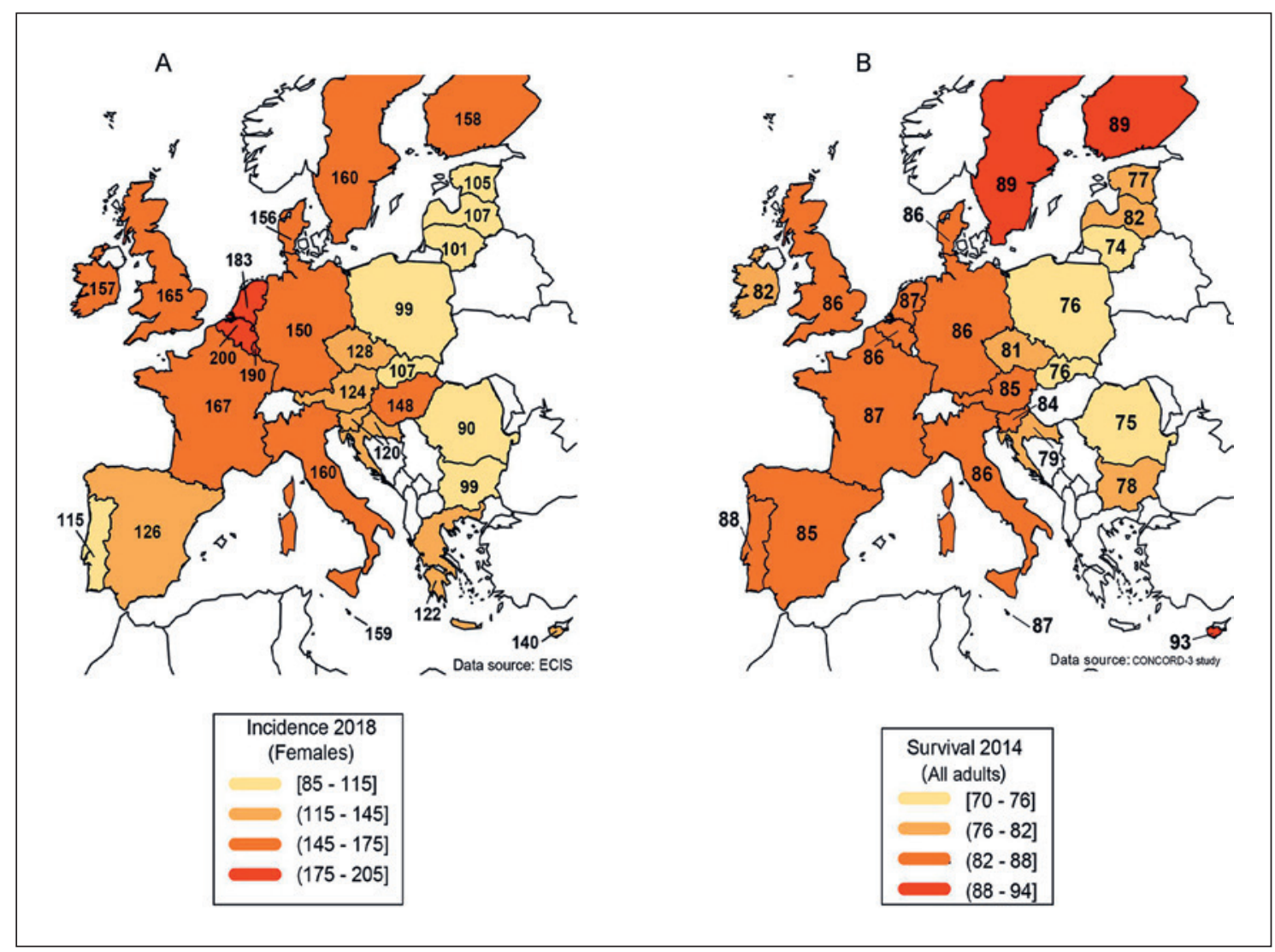

Fig. 1. Incidence and survival rates for breast cancer in EU-28 countries. A Age-standardized incidence rates in females (2018). Source: ECIS. B Five-year net survival rates for all adults (2010-2014). Source: CONCORD-3 study.

Finally, descriptive data on treatment availability in the EU-28 countries for the year 2014 were extracted from the ESMO European Consortium Study on the availability, out-of-pocket costs, and accessibility of antineoplastic medicines in Europe [17] and are summarized in stacked bar charts by GDP level (purchasing power parity [PPP] per capita in 2017; Fig. 5). The PPP categorization was created based on a natural cutoff identified in the incidence presentation. The high-PPP category includes affluent countries, ranked among the first 32 in the world, with a PPP in 2017 above USD 40,000 [18] (see note in Fig. 2).

All visualizations were performed using $\mathrm{R}$.

\section{Results}

\section{Incidence}

In Northern and Western Europe some of the highest breast cancer incidence rates worldwide have been recorded $[19,20]$. The incidence is highest in the high economic European countries, which include most of Northern and Western Europe, along with Italy and Malta from Southern Europe. In fact, all European countries ranked in 2017 among the top 31 in the world by GDP based on PPP per capita except for one, i.e., Austria, with a 2018 predicted incidence in the 2 highest incidence categories (above 145/100,000; Fig. 1a, 2). In addition, no country ranked below 31 by PPP (2017), except for Hungary, which has a predicted incidence above 140/100,000, creating a clear split for the 26 countries between the higher $(n=12)$ and lower PPP countries $(n=14)$.

In particular for Hungary, as with other countries without cancer registries, the 2018 ECIS incidence prediction is based on neighboring countries and seems to be an overestimate, not corresponding to Hungary's historical estimates for up to 2017, as given by the IHME. These are close to the other Central and Eastern European countries with which Hungary shares a similar PPP ranking (Fig. 3a).

In general, the same pattern mentioned with observation of high incidence in high PPP countries, is also seen across time (Fig. 3a). The lower incidence observed in the countries with low PPP, such as in Southern Europe and former Eastern Bloc countries from any other geographical region, persists across the period from 1990 to 2017 . In the first 15 years, an upward trend is apparent in almost all countries across regions and PPP levels, except for the UK, The Netherlands, and Austria, which exhibit a decreasing trend. From 2010, the incidence seems to plateau 


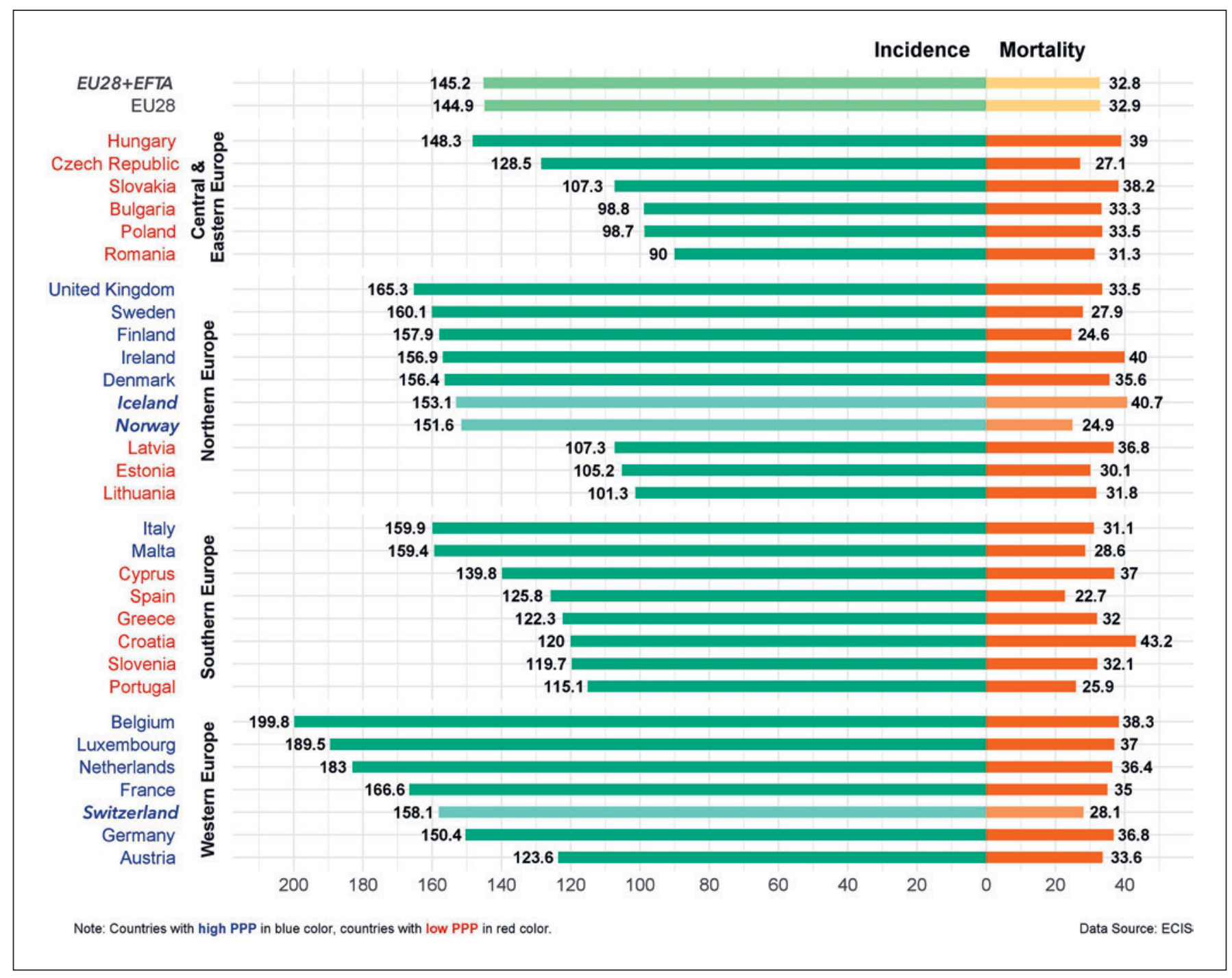

Fig. 2. Age-standardized incidence and mortality rates by region and country for female breast cancer in EU-28 countries (2018). Source: ECIS. Countries' PPP classification: high, blue; low, red. The names in italics are of the 3 countries in the EFTA.

or decrease for most countries, with the exception of 4 of the 6 Central and Eastern European countries (Bulgaria, Slovakia, Poland, and Romania) that exhibit a continuing increasing trend, towards the slightly higher incidence of Hungary and the Czech Republic.

It is noted that the behavior of Cyprus is not consistent with that of the other Southern European countries or countries in the same PPP category. The observed peak in incidence in 2007-2008 can be attributed to prevalent rounds of screening initiated in 2004 and extended to a nationwide level in 2007 [21].

The overall incidence and mortality remain identical when adding the 3 European Free Trade Association (EFTA) countries, all of which are affluent (high PPP) and have a predicted incidence above 150/100,000.
Age Trends

Generally, within the EU, in breast cancer incidence rates, the so-called Clemmensen's hook has been recorded, which indicates a progressively increasing risk with age with a change around age 50 years (i.e., around menopause) [22]. Studies exploring the effect of age on incidence rates, within EU countries, have identified differences between age groups before and after menopause [22-24]. Breast cancer in women is directly linked to a later onset of menopause [24], most likely caused by accumulating exposure to endogenous hormones [24]. As explored by Arnold et al. [23], who studied trends from 1998 to 2008 in $26 \mathrm{Eu}$ ropean countries, the incidence rate in postmenopausal women is much higher than in premenopausal women (range 70-500 compared to 40-160/100,000). Countryspecific differences are also detected. 


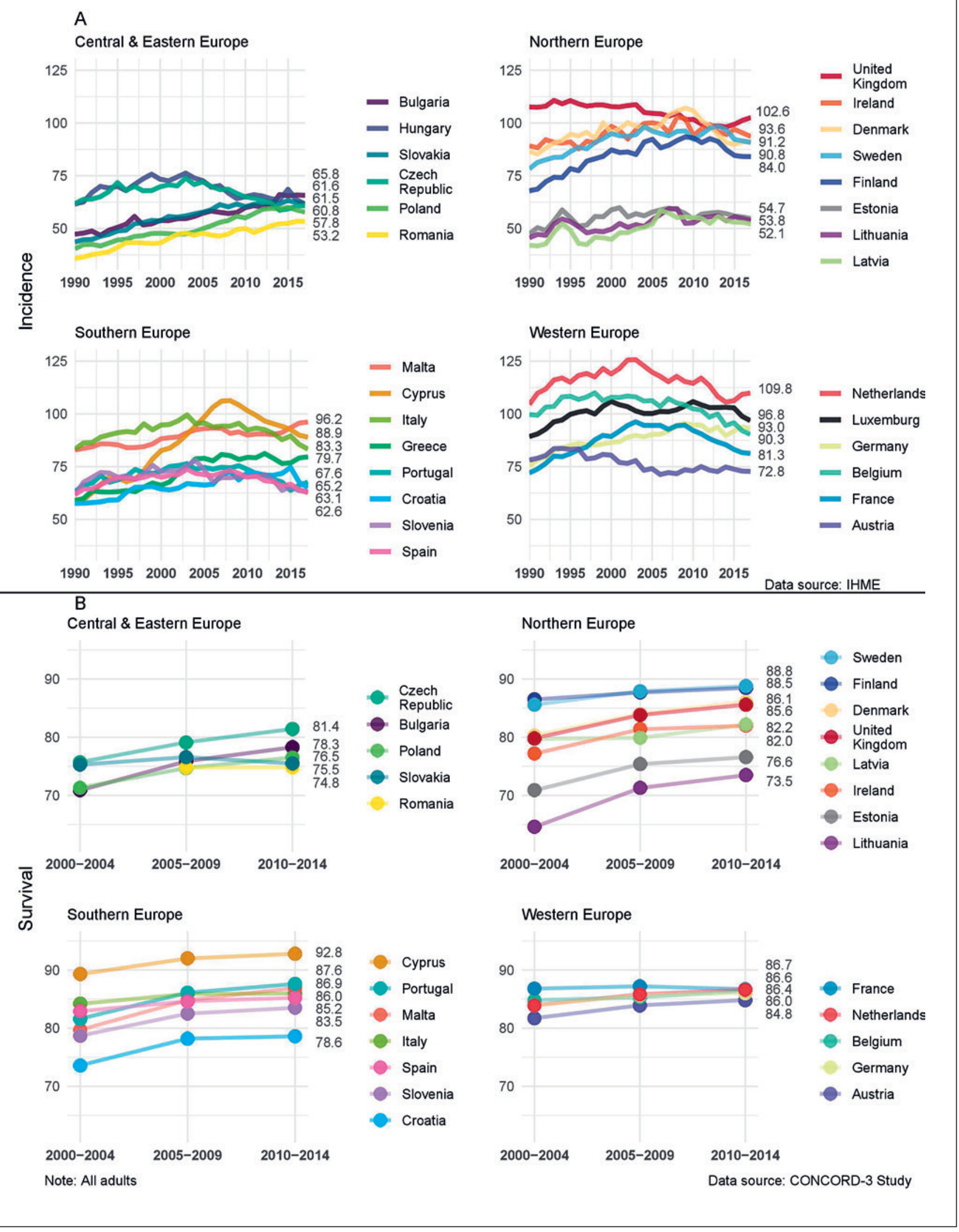

Fig. 3. Trends in breast cancer by country and region. A Age-standardized incidence rates in females (1990-2017). Source: IHME. B Five-year net survival rates in all adults (2000-2014). Source: CONCORD-3 study. Data is not available for Greece, Hungary, and Luxemburg. 


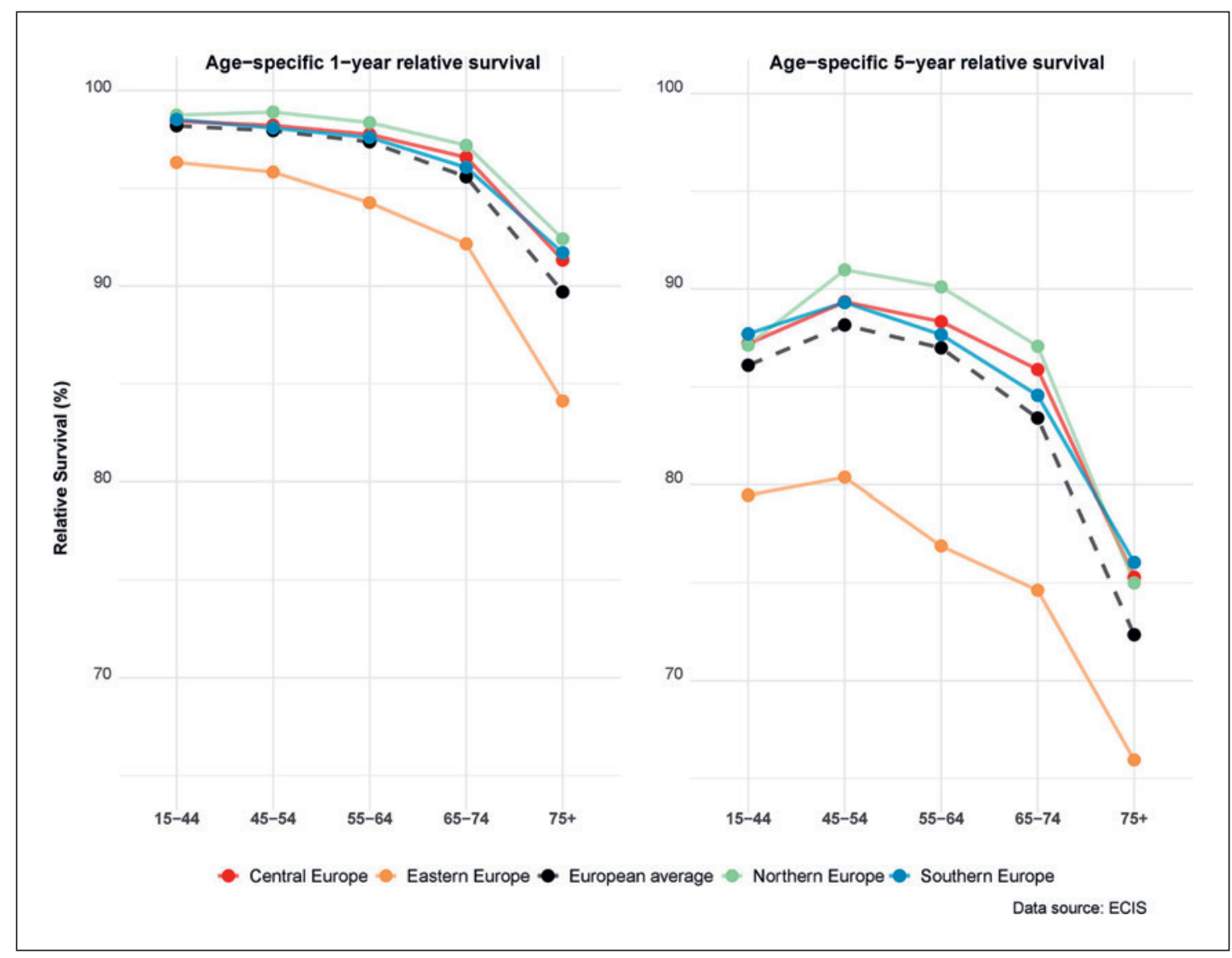

Fig. 4. One- and five-year net survival rates for breast cancer by age group and region (2000-2007). Source: ECIS. Data is not available for Greece, Cyprus, UK, Hungary, Luxembourg, and Romania.

\section{Survival}

Based on the most recent available data for 2010-2014 in the CONCORD-3 study, survival (5-year net survival age-adjusted probability in all adults), in the EU-28 countries [16] (Fig. 1b, 3b), ranges from $79 \%$ in Croatia to $93 \%$ in Cyprus; both are high and low outliers in Southern Europe. For Cyprus, the exceptionally high survival rate observed could be attributed to the detection of small, localized cancers, including overdiagnosis due to the introduction of screening $[21,25]$.

After Cyprus, the next higher survival rate (89\%) is observed in the Nordic countries (Sweden and Finland), followed by all countries in Western Europe. More precisely, high survival and homogeneity are observed in Western Europe, where all countries achieve a 5-year survival rate between 85 and $87 \%$, as well as in Southern Europe, where survival is similar (84-88\%) except for the aforementioned cases of Cyprus and Croatia. Survival in the other northern countries, i.e., Denmark (86\%), UK $(86 \%)$, and Ireland (82\%), is similarly close to that in Western Europe. Interestingly, although it has an incidence comparable to that of the Baltic countries, Latvia has a comparatively high survival (82\%) resembling those of the countries with a high PPP. Slovenia is another country with a relatively high survival rate $(84 \%)$ coupled with a relatively low incidence.

Distinctly lower is the survival reported for countries in the Central and Eastern European region. Only the Czech Republic exceeds the limit of $80 \%$, while all other countries display lower 5 -year survival rates between $75 \%$ (Romania) and 78\% (Bulgaria), including the 2 Baltic countries of Estonia and Lithuania (74 and 77\%). The lower survival rate is clustered in the countries of the former Eastern Bloc with relatively low PPP, with the exception of Latvia and Slovenia.

Exploring longitudinally the levels of survival by country from 2000 to 2014 (expressed in 5-year intervals), an increasing trend over time is observed consistently throughout Europe. In almost all countries, the rate of increase is higher in the earlier periods than in the latter.

\section{Age Trends}

The geographic categorization used here differs from the one used earlier and is described in Methods (source: ECIS) [1]. The 1 -year survival rate is over $90 \%$ for younger patients, while the highest 5-year survival is observed 


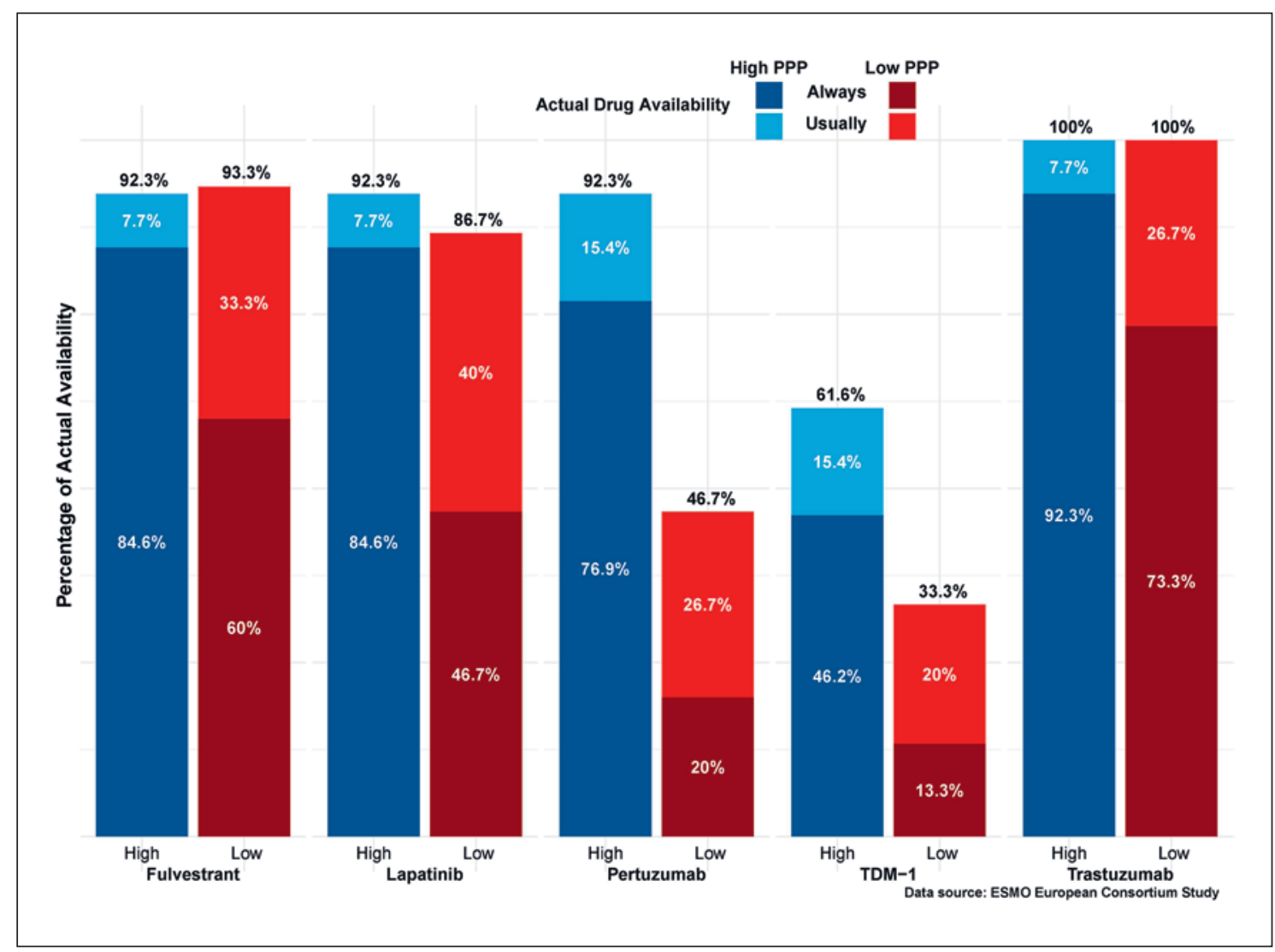

Fig. 5. Drug availability for metastatic breast cancer in high-/low-PPP countries (2014-2015). Source: ESMO European Consortium study on the availability of antineoplastic medicines.

for the 45- to 54-year-old group (Fig. 4). Both 1- and 5 -year relative survival rates are decreasing in patients with breast cancer aged 55 years and older, with a steeper decline at older ages (over 75 years). The decreasing trend is similar across regions, with Eastern Europe survival consistently at a lower level, reaching as low as $66 \%$ for older ages (over 75 years).

\section{Accessibility of Antineoplastic Medicines}

The EU-28 countries have been categorized into high and low PPP, as described earlier. The underlying assumption is that the observed increased survival apparent in the high PPP countries would also correspond to countries with a higher availability of crucial antineoplastic medicines. The actual availability across countries is presented for 5 treatments of metastatic breast cancer in Figure 5 [17]. The medicines under consideration include hormonal therapy with fulvestrant, and the newer expensive medications for HER2+ breast cancer lapatinib, pertuzumab, TDM-1, and trastuzumab. We see that, in fact, the "always" category for actual drug availability is consistently higher in the high-PPP countries than in the lower-PPP countries. The categories "half the time," "occasionally," "never," and "not available" are not shown.
What affects survival is not only the cost of drugs, and whether patients can receive them for free, at a nominal cost, or at full price, but also whether beneficial treatments are available to patients. When a treatment is available only usually or even worse occasionally or never, instead of always, it is obvious that less beneficial treatments are administered instead, with a negative impact on survival.

\section{Conclusion}

All EU countries are classified as developed economies, and action should be taken to eliminate the modifiable risk factors responsible for high breast cancer incidence rates. When comparing the EU-28 countries, it was shown that in the more affluent countries, usually the ones with a longer established Western lifestyle, a higher breast cancer incidence was indeed observed as has been previously reported [26]. In addition, these countries exhibit higher survival rates and, as shown in this paper, these higher rates are associated with the higher actual availability of important treatments. One can safely assume that differences between the higher- and lower-in- 
come countries include lifestyle, age at the first pregnancy, obesity, and probably the level of exposure to exogenous estrogens, as well as the disease stage at diagnosis and general access to high-quality care, all factors that affect breast cancer incidence and/or survival.

This review confirms previous findings that show a significant correlation between incidence and survival rates within European countries [27]. Survival rates for all EU countries show a significant increase, but most former Eastern Bloc European countries still record lower survival rates compared to other countries within the EU. In order to achieve the goal of reducing incidence rates and to eliminate discrepancies in survival rates, the custom needs of distinct regions should be taken into account. The overall survival improvement shown across all EU28 countries will probably be amplified as more of the Eastern Bloc countries reach a higher economic status and beneficial treatments become available to all European citizens.

Many complex factors underlie the variations in breast cancer incidence, mortality, and survival [28]. Nevertheless, our work shows that a good part of the differences in breast cancer incidence and survival rates between European countries can be better attributed to the difference in their (socio)economic status rather than their geographic (race and ethnicity) distribution on the European continent.

\section{Acknowledgement}

We thank Panagiota Zygoura, Georgia Dimopoulou, and Androniki Stavrou for their contribution to data visualization.

\section{Disclosure Statement}

The authors declare no conflict of interests.

\section{Funding Sources}

None.

\section{Author Contributions}

U.D. developed the concept for this review. All coauthors were responsible for literature review, data extraction, descriptive statistics, and visualization and contributed to the development of this paper.

\section{References}

1 European Commission. ECIS - European Cancer Information System. https://ecis.jrc. ec.europa.eu.

2 Cardoso F, Kyriakides S, Ohno S, PenaultLlorca F, Poortmans P, Rubio IT, et al. Early breast cancer: ESMO clinical practice guidelines for diagnosis, treatment and follow-up. Ann Oncol. 2019;30(8):1194-220.

3 Iwamoto Y, Kaucher S, Lorenz E, Bärnighausen T, Winkler V. Development of breast cancer mortality considering the implementation of mammography screening programs - a comparison of western European countries. BMC Public Health. 2019 Jun;19(1):823.

4 Eurostat. Statistics explained. https:// ec.europa.eu/eurostat/statistics-explained/ index.php/Cancer_statistics___specific_ cancers\#Breast_cancer ECS-SCSE.

5 Hermon C, Beral V. Breast cancer mortality rates are levelling off or beginning to decline in many western countries: analysis of time trends, age-cohort and age-period models of breast cancer mortality in 20 countries. Br J Cancer. 1996 Apr;73(7):955-60.

6 Ferlay J, Colombet M, Soerjomataram I, Dyba T, Randi G, Bettio M, et al. Cancer incidence and mortality patterns in Europe: estimates for 40 countries and 25 major cancers in 2018. Eur J Cancer. 2018 Nov;103:356-87.

7 Carioli G, Malvezzi M, Rodriguez T, Bertuccio P, Negri E, La Vecchia C. Trends and predictions to 2020 in breast cancer mortality in Europe. Breast. 2017 Dec;36:89-95.
8 United Nations. Country classifications: world economic situation and prospects. Geneva: UN; 2019.

9 Kumar S, Preetha G. Health promotion: an effective tool for global health. Indian J Community Med. 2012 Jan;37(1):5-12.

10 Gadzicki D, Evans DG, Harris H, JulianReynier C, Nippert I, Schmidtke J, et al. Genetic testing for familial/hereditary breast cancer-comparison of guidelines and recommendations from the UK, France, the Netherlands and Germany. J Community Genet. 2011 Jun;2(2):53-69.

11 Janavičius R. Founder BRCA1/2 mutations in the Europe: implications for hereditary breast-ovarian cancer prevention and control. EPMA J. 2010 Sep;1(3):397-412.

12 Levy-Lahad E, Lahad A, King MC. Precision medicine meets public health: population screening for BRCA1 and BRCA2. J Natl Cancer Inst. 2014 Dec;107(1):420.

13 Delivorias A, Sabbati G. EU demographic indicators: situation, trends and potential challenges. Brussels: European Parliamentary Research Service; 2015.

14 England K, Azzopardi-Muscat N. Demographic trends and public health in Europe. Eur J Public Health. 2017;27:9-13.
15 Fitzmaurice C, Akinyemiju TF, Al Lami FH, Alam T, Alizadeh-Navaei R, Allen C, et al.; Global Burden of Disease Cancer Collaboration. Global, regional, and national cancer incidence, mortality, years of life lost, years lived with disability, and disability-adjusted lifeyears for 29 cancer groups, 1990 to 2016: a systematic analysis for the Global Burden of Disease Study. JAMA Oncol. 2018 Nov;4(11): 1553-68.

16 Allemani C, Matsuda T, Di Carlo V, Harewood R, Matz M, Nikšić M, et al.; CONCORD Working Group. Global surveillance of trends in cancer survival 2000-14 (CONCORD-3): analysis of individual records for 37513025 patients diagnosed with one of 18 cancers from 322 population-based registries in 71 countries. Lancet. 2018 Mar;391(10125): 1023-75.

17 Cherny N, Sullivan R, Torode J, Saar M, Eniu A. ESMO European Consortium Study on the availability, out-of-pocket costs and accessibility of antineoplastic medicines in Europe. Ann Oncol. 2016 Aug;27(8):1423-43.

18 Worldometeres [Internet]. GDP per capita [cited 2019 Sep 3]. Available from: https:// www.worldometers.info/gdp/gdp-per-capita/.

19 Torre LA, Islami F, Siegel RL, Ward EM, Jemal A. Global Cancer in Women: burden and Trends. Cancer Epidemiol Biomarkers Prev. 2017 Apr;26(4):444-57. 
20 Boffetta P, Boccia S, La Vecchia C. A quick guide to cancer epidemiology. Berlin: Springer; 2019.

21 Cooter M, Soliman AS, Pavlou P, Demetriou A, Orphanides C, Kritioti E, et al. Incidence and time trends of cancer in Cyprus over 11 years (1998-2008). Tumori. 2015 Jan-Feb; 101(1):8-15.

22 Kruijshaar ME, Barendregt JJ; European Disability Weights Group. The breast cancer related burden of morbidity and mortality in six European countries: the European Disability Weights project. Eur J Public Health. 2004 Jun;14(2):141-6.
23 Arnold M, Karim-Kos HE, Coebergh JW, Byrnes G, Antilla A, Ferlay J, et al. Recent trends in incidence of five common cancers in 26 European countries since 1988: Analysis of the European Cancer Observatory. Eur J Cancer. 2015 Jun;51(9):1164-87.

24 Thun MJ, Linet MS, Cerhan JR, Haiman C, Schottenfeld D. Schottenfeld and Fraumeni cancer epidemiology and prevention. 4th ed. New York: Oxford University Press; 2018.

25 Ellis L, Woods LM, Estève J, Eloranta S, Coleman MP, Rachet B. Cancer incidence, survival and mortality: explaining the concepts. Int J Cancer. 2014 Oct;135(8):1774-82.
26 Znaor A, van den Hurk C, Primic-Zakelj M, Agius D, Coza D, Demetriou A, et al. Cancer incidence and mortality patterns in South Eastern Europe in the last decade: gaps persist compared with the rest of Europe. Eur J Cancer. 2013 May;49(7):1683-91.

27 De Angelis R, Sant M, Coleman MP, Francisci S, Baili P, Pierannunzio D, et al.; EUROCARE-5 Working Group. Cancer survival in Europe 1999-2007 by country and age: results of EUROCARE-5-a population-based study. Lancet Oncol. 2014 Jan;15(1):23-34.

28 Hortobagyi GN, de la Garza Salazar J, Pritchard K, Amadori D, Haidinger R, Hudis CA, et al.; ABREAST Investigators. The global breast cancer burden: variations in epidemiology and survival. Clin Breast Cancer. 2005 Dec;6(5):391-401. 